\title{
Pulmonary Dirofilariasis with Serologic Study on Familial Infection with Dirofilaria immitis
}

\author{
Shin-ichiro Mori, Yasunobu HiRotsu*, Akira Mizoguchi, Masaharu KaWABATA, \\ Fukumi NAKAMURA-UCHIYAMA**, Yukifumi NAWA** and Mitsuhiro OsamE
}

\begin{abstract}
An asymptomatic patient with a pulmonary coin lesion surgically diagnosed with pulmonary dirofilariasis caused by infection with Dirofilaria immitis (D. immitis) is presented. The preoperative stored serum of the patient was positive for $D$. immitis by enzyme-linked immunosorbent assay (ELISA). A family study showed that three of five family members were seropositive for $D$. immitis. These results suggest that family members of a patient with pulmonary dirofilariasis were frequently exposed to $D$. immitis and serodiagnostic methods are useful for detecting subclinical infection of $D$. immitis.

(Internal Medicine 43: 327-330, 2004)
\end{abstract}

Key words: pulmonary dirofilariasis, Dirofilaria immitis, family study, enzyme-linked immunosorbent assay, zoonosis, coin lesion

\section{Introduction}

Human pulmonary dirofilariasis is a zoonotic parasitic disease caused by infection with canine filaria, Dirofilaria immitis (D. immitis). D. immitis is found worldwide and parasitizes preferentially in the right ventricle and pulmonary arteries of dogs. The parasites are usually transmitted by mosquitoes and are capable of infecting humans (1-3). The prevalence of $D$. immitis infection in dogs is high throughout the world, and recently, the number of pulmonary dirofilariasis in humans has increased (4-10). Epidemiological studies revealed a close association of the occurrence of human pulmonary dirofilariasis with the distribution of canine dirofilariasis $(4,5,7,8)$. Because dirofilariasis is a vector-borne disease, the prevalence of the disease is influenced by the frequency of exposure to the bite of infected mosquitoes $(2,4)$. We present here a patient with surgically diagnosed pulmonary dirofilariasis whose serum antibody titer to D. immitis was examined before and after surgical treatment. We also examined the sera of his family members for the presence of antibody to $D$. immitis because, in endemic areas of dirofilarial infection, the possibility of familial infection with the parasite may be high.

\section{Case Report}

A 42-year-old man consulted our department after routine chest roentgenographic examination revealed pulmonary coin lesion in the left lower lobe. He had no respiratory symptoms and no history of respiratory illness. He was a non-smoker and had no pets at home. Physical examination was normal. White blood cell count (WBC) in peripheral blood was $4,600 / \mathrm{mm}^{3}$ with an eosinophil count of $92 / \mathrm{mm}^{3}$. C-reactive protein was negative and serum concentration of immunoglobulin E (IgE) was $180 \mathrm{U} / \mathrm{ml}$. A chest roentgenogram and computed tomographic scan revealed a solitary subpleural nodular shadow in the left lower lobe (Fig. 1). Since we could not make a diagnosis by bronchofiberscopy, the patient underwent a thoracotomy with wedge resection of the left $\mathrm{S}^{6}$ segment under the suspicion of malignant neoplasm. A granulomatous nodule was observed in the resected specimen. Histopathological examination revealed cross-sections of a parasite, identified morphologically as $D$. immitis, which embolized the branch of pulmonary artery that was surrounded by the granulomatous lesion (Fig. 2). The patient was discharged 17 days after the operation without additional treatment.

\section{Serologic studies}

The patient's preoperative stored serum was first screened using multiple-dot enzyme-linked immunosorbent assay

From the Third Department of Internal Madicine, Kagoshima University School of Madicine, Kagoshima, *the Department of Surgery, Minami Kyushyu National Sanatorium, Kagoshima and **the Department of Parasitology, Miyazaki Medical College, Miyazaki

Received for publication May 23, 2003; Accepted for publication November 10, 2003

Reprint requests should be addressed to Dr. Shin-ichiro Mori, the Department of Internal Medicine, Southern Region Hospital, 220 Midori Machi, Makurazaki, Kagoshima 898-0011 


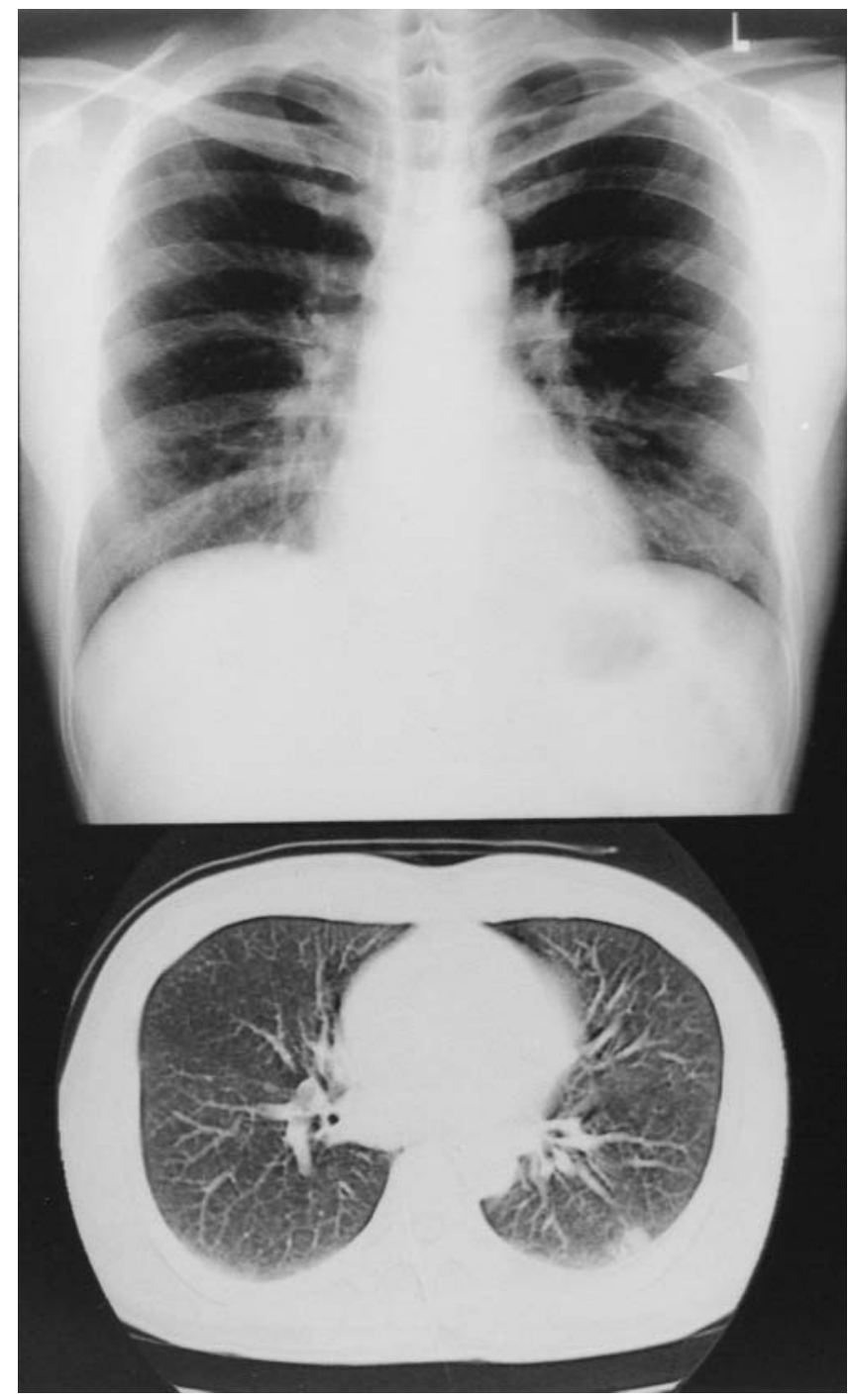

Figure 1. A chest radiograph and computed tomographic scan showing a solitary subpleural nodular shadow in the left lower lobe.

(ELISA), in which 12 different parasite antigens, including $D$. immitis, were spotted on a piece of nitrocellulose membrane (HAWG304FO, Millipore, MA, USA) (11). The filter was incubated with the patient's sera, diluted at $1: 200$, washed, and then incubated with peroxidase-conjugated rabbit anti-human IgG (DAKO, Glostrup, Denmark). Antibody binding was developed by incubation in a reaction mixture containing $\mathrm{H}_{2} \mathrm{O}_{2}$ as the substrate and 4-chloro-1-naphthol as the chromogen. The developed color of each parasite antigen spot was visually scored. The patient's preoperative serum moderately bound to $D$. immitis antigen with weak crossreactions to other nematode antigens (not shown).

To evaluate the possibility of residual worms, specific antibody titers to D. immitis in the patient's sera were examined by microplate ELISA both before and two months after

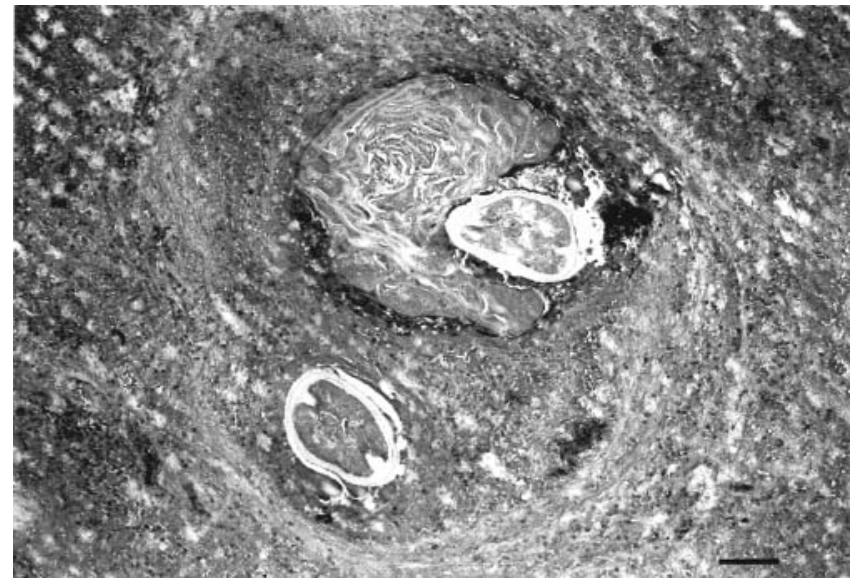

Figure 2. Transverse section of Dirofilaria immitis embolized pulmonary artery (HE stain, Bar=100 $\mu \mathrm{m})$.

surgery. Wells of microtiter plates (Nunc, Roskilde, Denmark) were coated with $10 \mu \mathrm{g} / \mathrm{ml}$ of $D$. immitis antigen. Wells were then blocked with Tris-buffered saline containing $1 \%$ casein and incubated with the patient's serially diluted sera. After washing, peroxidase-labeled rabbit anti-human $\operatorname{IgG}$ was added and incubated for 1 hour. ABTS (2, 2'azino-di[3-ethyl-benzthiazoline sulfonate]) was used as substrate and optical densities were read in a Labsystems Multiskan Bichromatic (Labosystem Oy, Helsinki, Finland). As shown in Table 1, the antibody level in the serum decreased two months after the surgical resection of the pulmonary nodule.

\section{Family studies}

The patient and his family members were born and lived on Nagashima, a small island in the northwestern area of Kagoshima prefecture, Kyushyu, Japan. We interviewed all family members and investigated their environs. All family members were healthy, had not experienced any respiratory symptoms or skin lesions and had no previous respiratory illness. They had never kept dogs or other pets, although four neighbors did own dogs. Every summer, mosquitoes invaded the family's house. We explained the possibility of familial infection with the parasite, and, with informed consent, examined the antibody to D. immitis in their sera using ELISA. The results are shown in Table 1. In addition to the present patient, three of five family members were seropositive for D. immitis, and two seropositive children had elevated total $\operatorname{IgE}$ in their sera. The three seropositive family members had no abnormalities on subsequent chest roentgenogram.

\section{Discussion}

The preoperative diagnosis of pulmonary dirofilariasis is difficult because of the lack of characteristic symptoms, laboratory and roentgenographic findings. Although a 
Familial Exposure to Dirofilaria immitis

Table 1. Findings of Clinical, Laboratory and Serologic Examinations of Family Members

\begin{tabular}{lcccccc}
\hline Subject* & $\begin{array}{c}\text { Age (years) } \\
\text { /Gender }\end{array}$ & $\begin{array}{c}\text { Chest X-ray } \\
\text { Findings }\end{array}$ & $\begin{array}{c}\text { WBC } \\
\left(/ \mathrm{mm}^{3}\right)\end{array}$ & $\begin{array}{c}\text { Eosinophil } \\
\left(/ \mathrm{mm}^{3}\right)\end{array}$ & $\begin{array}{c}\text { IgE } \\
(\mathrm{U} / \mathrm{ml})\end{array}$ & $\begin{array}{c}\text { Antibody to } \\
\text { D. immitis** }\end{array}$ \\
\hline 1 (case) & $42 / \mathrm{M}$ & coin lesion & 4,600 & 92 & 180 & $0.830^{* * *}$ (pre-op) \\
2 & & & & & & 0.546 (post-op) \\
3 & 38/W & $\mathrm{N}$ & 7,800 & 312 & 16 & 0.164 \\
4 & $15 / \mathrm{M}$ & $\mathrm{N}$ & 6,600 & 396 & 180 & 0.082 \\
5 & $14 / \mathrm{W}$ & $\mathrm{N}$ & 7,000 & 420 & 940 & 0.385 \\
6 & $12 / \mathrm{M}$ & $\mathrm{N}$ & 6,800 & 476 & 2,700 & 0.158 \\
\hline
\end{tabular}

M: man, W: woman, N: normal, WBC: white blood cell, IgE: immunoglobulin E. *Subject No. 2 is patient's wife. Subject No. 3-6 are patient's children. $* * D$. immitis: Dirofilaria immitis. $* * * O D$ value at serum dilution of $1: 300$ (cut-off value O.D. $=0.100$ was determined as mean $+3 \mathrm{SD}$ of the $\mathrm{OD}$ value of normal healthy volunteers).

pulmonary coin lesion is a typical clinical form of dirofilariasis, such lesions have often been surgically resected under a suspicion of malignant neoplasm or other pulmonary diseases. The diagnostic procedure and the clinical findings of the patient were typical for pulmonary dirofilariasis as previously described. After obtaining the pathological diagnosis, we found that the patient's preoperative stored serum was positive for $D$. immitis. The serologic methods, including ELISA, have routinely been used for diagnosis and research of D. immitis infection in dogs (12-14) as well as diagnosis in humans $(15,16)$. These methods cannot be used to rule out a diagnosis of neoplastic lesion or other pulmonary diseases. Instead, serologic methods are most useful in follow-up studies after treatment and in the epidemiological survey for $D$. immitis infection $(5,7,8,15)$.

The zoonotic transmission of $D$. immitis from infected animals to humans is mediated by mosquitoes. A few seroepidemiological studies for $D$. immitis infection in humans show a close association of the prevalence of human pulmonary dirofilariasis with that of canine dirofilariasis (4, $5,7,8)$. The present patient's home and neighborhood environment seemed to increase the risk of dirofilarial infection. Using serologic methods, we found in this study that, of the patient's family members, three of five were seropositive for $D$. immitis. These results suggest that the patient's family members have been frequently exposed to infection with $D$. immitis.

The clinical usefulness of a serologic survey of $D$. immitis, including a family survey for earlier diagnosis of pulmonary dirofilariasis, has not been sufficiently studied. Alvarez et al detected a subclinical patient with pulmonary dirofilariasis in a mass serologic survey for $D$. immitis (8). A serologic survey of family members of patients with dirofilariasis may be useful for earlier detection of subclinical infection by the parasite, especially when the subjects are living in an environment with a risk of dirofilarial infection.

In the present patient, the eosinophil count in peripheral blood and the serum concentration of IgE were normal. Previous reviews stated that eosinophilia is not frequent in pulmonary dirofilariasis $(4,9,17)$. In the present study, of the three seropositive family members, two had slight eosinophilia with an elevated concentration of serum IgE, while the other (the patient's wife) showed normal levels. These differences in laboratory findings among seropositive individuals may be due to the difference in the degree and phase of anti-parasitic immune response, the difference in the amount of injected parasites from vector mosquitoes, and the mortality of injected parasites in the host. It is important to note that the seropositive family members had no abnormal findings on chest X-ray examination. The occurrence of pulmonary dirofilariasis from seropositive individuals may also be influenced by several factors such as the degree of anti-parasitic response and the number of injected parasites in the host.

In contrast to dogs, a counterplan for subclinically infected humans with $D$. immitis has not been established. Because, it is generally believed that $D$. immitis cannot live in human subcutaneous tissue (2), the serum antibody to the parasite may decrease with time after inoculation by infected mosquitoes. Konishi (18) reported the yearly change in serum antibody to D. immitis in inhabitants of a city with a high seroprevalence of $D$. immitis in dogs. He reported that $10.0 \%$ of the inhabitants examined showed an increased level of serum antibody to $D$. immitis one year later, suggesting that inhabitants in the city were frequently exposed to infected mosquito bites during the year. In this report, it was also demonstrated that $64.4 \%$ of seropositive individuals showed a decreased level of serum antibody to the parasite one year later. This report suggests that many inhabitants could be repeatedly exposed to $D$. immitis in the environment with a high risk of dirofilarial infection, and exposure to the parasite may have a transitory effect in many individuals. However, there is currently little information available on the change in antibody to the parasite over time and the incidence of pulmonary dirofilariasis in asymptomatic seropositive individuals. We advised the three seropositive family members to have periodic medical follow-up for pulmonary lesions and serum antibody titer to D. immitis. Further pedioric examination of serum antibody may be useful for detecting persistent infection in these individuals. We 
also advised active extermination of mosquitoes. Although we could not obtain informed consent to examine the neighboring dogs and their owners for the presence of dirofilarial infection in the present study, a mass survey may be helpful for the clarification and prevention of dirofilarial infection.

In conclusion, the present results show that D. immitis infection can occur frequently among family members of a patient with pulmonary dirofilariasis. An extensive survey of family members may be useful for earlier detection of subclinical infection of $D$. immitis, especially when patients are living in environments with a high risk of dirofilarial infection.

Acknowledgements: We thank Dr. Norihiro Yasuda and Dr. Masao Akusawa (Department of Veterinary Medicine, University of Kagoshima) for veterinary advice.

\section{References}

1) Beaver PC, Orihel TC. Human infection with firaliae of animals in the United States. Am J Trop Med Hyg 14: 1010-1029, 1965.

2) Grieve RB, Lok JB, Glickman LT. Epidemiology of canine heartworm infection. Epidemiol Rev 5: 220-246, 1983.

3) Gutierrez Y. Diagnostic features of zoonotic firaliae in tissue sections. Hum Pathol 15: 514-525, 1984.

4) Ciferri F. Human pulmonary dirofilariasis in the United States: a critical review. Am J Trop Med Hyg 31: 302-308, 1982.

5) Scherr BA, Scherr GH. How many humans have canine heartworm? Diag Med May/June: 95-96, 1983.

6) Yoshimura H, Akao N. Current status of human dirofilariasis in Japan. Int J Zoonoses 12: 53-60, 1985.
7) Konishi E. Culex triaeniorhynchus and Ades albopietus (Diptera: Culicidae) as natural vectors of Dirofilaria immitis (Spirurida: Filariidae) in Miki City, Japan. J Med Entomol 26: 294-300, 1989.

8) Alvarez AM, Sanchez MC, Martin JM, Martin FS. Seroepidemiological studies on human pulmonary dirofilariasis in Spain. Ann Trop Med Parasitol 84: 209-213, 1990.

9) Asimacopoulos PJ, Katras A, Christie B. Pulmonary dirofilariasis. the largest single-hospital experience. Chest 102: 851-855, 1992.

10) Milanez de Campos JR, Valent Barbas CS, Brito Filomeno LT, et al. Human pulmonary dirofilariasis: analysis of 24 cases from Sao Paulo, Brazil. Chest 112: 729-733, 1997.

11) Maruyama H, Noda S, Nawa Y. Emerging problems of parasitic diseases in southern Kyushu, Japan. Jpn J Parasitol 45: 192-200, 1996.

12) Wong MM, Suter PF. Indirect fluorescent antibody test in occult dirofilariasis. Am J Vet Res 40: 414-420, 1979.

13) Grieve RB, Mika-Johnson M, Jacobson RH, Cypess RH. Enzymelinked immunosorbent assay for measurement of antibody responses to Dirofilaria immitis in experimentally infected dogs. Am J Vet Res 42: 66-69, 1981.

14) Grieve RB, Knight DH. Anti-Dirofilaria immitis antibody levels before and after antihelmintic treatment of experimentally infected dogs. J Parasitol 71: 56-61, 1985.

15) Glickman LT, Grieve RB, Schantz PM. Serologic diagnosis of zoonotic pulmonary dirofilariasis. Am J Med 80: 161-164, 1986.

16) Ohnishi Y, Yoshimura H, Ohyama T, Tokairin M, Nagakura M. An attempt of immunodiagnosis by means of mixed passive hemagglutination (MPHA) test for human pulmonary dirofilariasis. Parasitol Res 74: 277-280, 1988.

17) Robinson NB, Chavez CM, Conn JH. Pulmonary dirofilariasis in man: a case report and review of the literature. J Thorac Cardiovasc Surg 74: 403-408, 1977.

18) Konishi E. Yearly change in antibody level to Dirofilaria immitis (Spiruriada: Filariidae) among humans exposed naturally to infected mosquitoes. J Med Entomol 26: 489-490, 1989. 